\title{
Coastal deformation associated with the 2007 Noto Hanto earthquake, central Japan, estimated from uplifted and subsided intertidal organisms
}

\author{
Yasuo Awata ${ }^{1}$, Shinji Toda ${ }^{1}$, Heitaro Kaneda ${ }^{1}$, Takashi Azuma ${ }^{1 *}$, Haruo Horikawa ${ }^{1}$, \\ Masanobu Shishikura ${ }^{1}$, and Tomoo Echigo ${ }^{2}$ \\ ${ }^{1}$ Geological Survey of Japan, National Institute of Advanced Industrial Science and Technology (AIST), \\ Site 7, Higashi 1-1-1, Tsukuba 305-8567, Japan \\ ${ }^{2}$ Geo-Research Institute, Itachibori 4-3-2, Osaka 550-0012, Japan
}

(Received June 30, 2007; Revised October 19, 2007; Accepted October 23, 2007; Online published November 7, 2008)

\begin{abstract}
The March 25, 2007 Noto Hanto earthquake $\left(M_{\mathrm{j}}=6.9, M_{\mathrm{w}}=6.7\right)$ generated vertical crustal movement along the northwestern coast of the Noto Peninsula, central Japan. Soon after the event, we estimated the pattern and amount of coseismic coastal movement based on uplifted and subsided intertidal sessile organisms. Our observations reveal a broad 20-km-wide asymmetric zone of surficial deformation above and across the southdipping source fault, with a steep north-facing frontal limb and a gentle south-facing back limb. The maximum coseismic uplift was approximately $40 \mathrm{~cm}$ at the crest of the zone of deformation. The result of forward modeling suggests that the top of the south-dipping source fault is buried at a depth of approximately $2 \mathrm{~km}$, and that $1.2 \mathrm{~m}$ of slip on the fault provides the best fit to our surface observations. Our results demonstrate that traditional field investigations should be combined with modern instrumental observations such as GPS and InSAR to obtain the most effective and reliable spatio-temporal estimates of crustal movement associated with large earthquakes.
\end{abstract}

Key words: 2007 Noto Hanto earthquake, coseismic crustal movement, coastal uplift, intertidal organisms, concealed reverse fault.

\section{Introduction}

At 9:42 a.m. JST (Japan Standard Time; GMT+9) on March 25, 2007, a large earthquake occurred in the vicinity of the Noto Peninsula on the Japan Sea side of central Japan. The Japan Meteorological Agency (JMA) estimated the source parameters as follows: epicenter, $37.220^{\circ} \mathrm{N}$, $136.985^{\circ} \mathrm{E}, 11 \mathrm{~km}$ deep; $M_{\mathrm{j}}$ (JMA magnitude) $=6.9$; $M_{\mathrm{w}}=6.7$. Small tsunamis of up to $0.2 \mathrm{~m}$ in wave height were recorded at the tide gauge stations located at the ports of Nagahashi and Kanazawa, situated approximately $50 \mathrm{~km}$ east-northeast and approximately $70 \mathrm{~km}$ south-southwest of the epicenter, respectively. The locations of the main shock and aftershocks were concentrated on the hanging wall side of a previously mapped active submarine fault, the F-14 Fault (Fig. 1; Katagawa et al., 2005), which strikes east-northeast and dips to the south-southeast. However, no active faults have been mapped onshore in this region except for the north-northeast-striking Sakami Fault (Research Group for Active Faults of Japan, 1991), which is located further to the south. These observations suggest that the 2007 earthquake can be ascribed to a rupture of the F-14 Fault near the coastline of the Noto Peninsula.

Significant coseismic crustal uplift along the coastline of

*Now at Research and Development Bureau, Ministry of Education, Culture, Sports, Science and Technology, Kasumigaseki 3-2-2, Tokyo 1008959, Japan.

Copyright (c) The Society of Geomagnetism and Earth, Planetary and Space Sciences (SGEPSS); The Seismological Society of Japan; The Volcanological Society of Japan; The Geodetic Society of Japan; The Japanese Society for Planetary Sciences; TERRAPUB the western Noto Peninsula, where tidal variation as small as $30-40 \mathrm{~cm}$ facilitates the recognition of minor coastal deformation, is indicated by the generation of small tsunamis, the magnitude and focal mechanism of the main shock, and the distribution of aftershocks. In an effort to promptly determine the coastal deformation and source fault parameters, we conducted an urgent field survey of uplifted and subsided intertidal sessile organisms in the mezoseismal region.

\section{Methods}

We used four biomarkers of intertidal sessile organisms to measure the emergence and submergence of the coastline: the upper bounds of Ostreidae (oyster; Fig. 2), Mytilidae (mussel), and Pomatoleios kraussii (a type of tube worm; Fig. 2), and the abrupt boundary between Chlorophyceae (green algae) and Phaeophyceae (brown algae). Ostreidae, which is the most conspicuous intertidal organism in the wave-sheltered ports along the coastline, can be seen in Fig. 2 to form an approximately 20- to 40-cm-wide zonal colony on the quay wall; it usually co-exists with plants of Chlorophyceae and is found above the community of Phaeophyceae. The upper zone of Mytilidae colonies often overlap the lower zone of Ostreidae colonies. Based on the coexistence characteristics and zonation (Shinkawa, 1988), the Ostreidae colony probably consists of midlittoral Crassostrea gigas and/or Saccostrea Kegaki, although we were unable to confidently identify the species of individual Ostreidae in the field. P. kraussii forms colonial zonation or patches on wave-exposed rocky shores and exists 


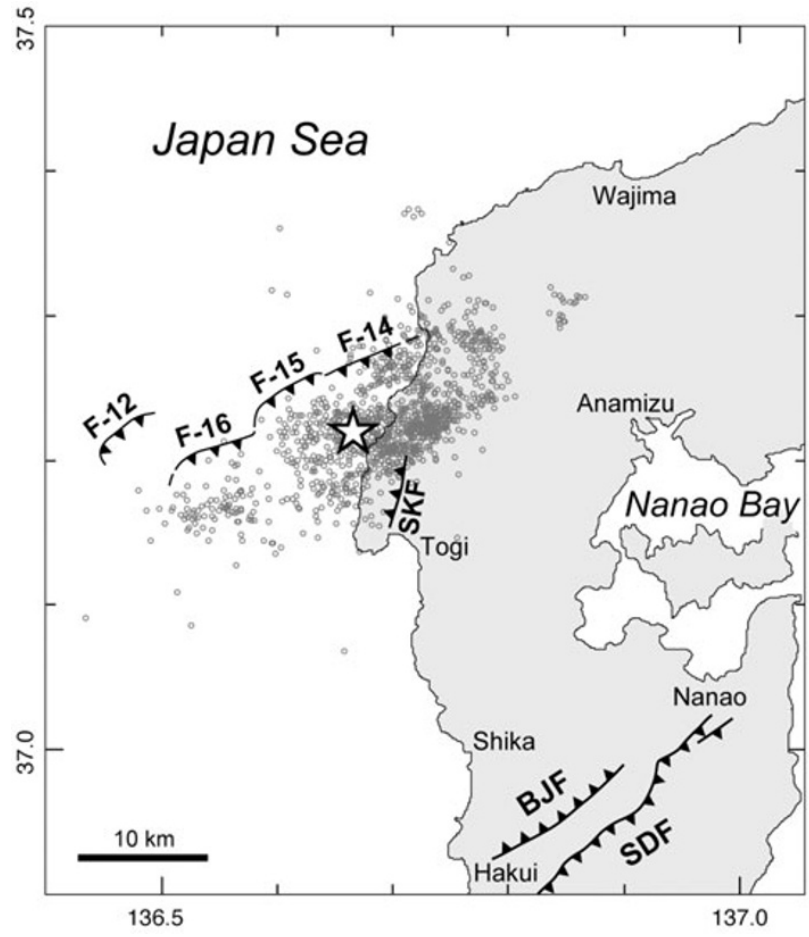

Fig. 1. Active onshore and offshore reverse faults in and around the epicentral area of the 2007 Noto Hanto earthquake. The teeth represent the upthrown side. Locations of the main shock and aftershocks determined by Japan Meteorological Agency are also shown. The offshore faults, F-12, F-14, F-15, and F-16, were discovered by Katagawa et al. (2005), whereas the location of the major inland active faults are derived from the Research Group for Active Faults of Japan (1991). SKF, Sakami Fault; BJF, Bijosan Fault; SDF, Sekidosan Fault.

together with plants of Chlorophyceae and animals of Saccostrea Kegaki in various locations.

We surveyed the coastline of the Noto Peninsula using an ordinary measuring tape to record the heights or depths of those biomarkers relative to sea level, which was taken as the midrange between the highest and lowest elevations of several waves. At each site, we usually observed the biomarker twice or three times on different days, and each time, we conducted five measurements using the same biomarker at different locations. The average of the measured heights or depths was then adjusted to the mean sea level based on the tidal gauge record at Wajima, which is approximately $30 \mathrm{~km}$ northeast of the epicenter (Fig. 1). As the tide gauge record shows long-period (10-30 min) sea level fluctuations of up to approximately $10 \mathrm{~cm}$ due to longperiod waves, which may be ascribed to regional weather conditions, we smoothed out this possible local effect by calculating 1-h central moving averages of the tide records. These smoothed-out values were used for the adjustments.

To be able to convert the obtained biomarker heights or depths to amounts of coseismic movement, it is necessary to know the heights or depths of these biomarkers prior to the earthquake. Fortunately, we found an Ostreidae colony at the port of Wajima, where a permanent GPS station revealed a coseismic uplift of $4 \mathrm{~cm}$ (Geographical Survey Institute, 2007). The upper bound of the colony was measured to be $2 \pm 3 \mathrm{~cm}$ above the mean sea level in 2001-2005, indicating that the Ostreidae biomarker was $2 \mathrm{~cm}$ below the mean

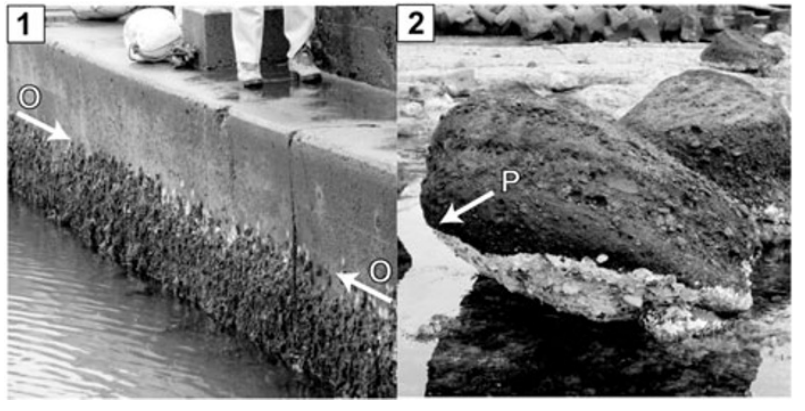

Fig. 2. Uplifted intertidal organic markers at Tsurugiji. 1: The upper boundary of an Ostreidae colony (O) at the port of Tsurugiji is located $39 \mathrm{~cm}$ above mean sea level (a.m.s.l.). Sea level at the time of measurement was $-3 \mathrm{~cm}$ a.m.s.1. 2: The upper boundary of a Pomatoleios kraussii cluster $(\mathrm{P})$ located on a wavy reef north of Tsurugiji port is a maximum of $41 \mathrm{~cm}$ a.m.s.l. Sea level at the time of measurement was $-4 \mathrm{~cm}$ a.m.s.l. P. kraussii shows an uneven upper colonial boundary.

sea level before the earthquake. Based on the positions of other biomarkers relative to those of Ostreidae, as determined from post-earthquake observations, we estimated the pre-earthquake heights of $P$. kraussii, Mytilidae, and algae biomarkers to be $+2 \mathrm{~cm},-12 \mathrm{~cm}$, and $-23 \mathrm{~cm}$, respectively, relative to mean sea level (Table 1). These estimates enabled us to calculate the amount of coseismic uplift or subsidence at individual sites. The range in measurement values recorded at individual sites was generally less than several centimeters, with the exception of measurements of $P$. kraussii, which lives in the wavy reef sections of the coast (Table 1).

The field measurements were conducted during three different time intervals: March 26-31, April 3-6, and April 21-23, 2007.

\section{Vertical Coastal Movement}

We determined the amount of coseismic uplift or subsidence at 45 sites along the coast of the Noto Peninsula: 42 sites were along the west coast and three were along the east coast (Fig. 3). No postseismic deformations beyond the errors of our measurements were recognized, and our results are largely consistent with continuous GPS observations undertaken at Togi, Shika, Anamizu, and Notojima (Geographical Survey Institute, 2007; open triangles in Fig. 3).

Figure 4 shows a profile of the determined crustal deformation along the west coast of the peninsula, projected to an azimuth of $\mathrm{N} 30^{\circ} \mathrm{W}$, which is approximately perpendicular to the F-14 Fault shown in Fig. 1. Our profile shows a broad 20-km-wide asymmetric zone of surficial deformation above and across the inferred source fault. The maximum uplift of approximately $40 \mathrm{~cm}$ was measured at Tsurugiji, close to the center of the uplifted section of the coast, on the north of which a steep frontal limb appears. The amount of uplift rapidly decreases by approximately two thirds over a short distance of $1.5 \mathrm{~km}$ - from $34 \mathrm{~cm}$ at Kuroshima to $11 \mathrm{~cm}$ at northwest Kaiso. Further to the north, minor subsidence of less than $10 \mathrm{~cm}$ occurs from Fukami to Unyu. Southward from Tsurugiji, the amount of uplift gradually decreases to almost zero around Uwano, defining a gentle back limb. The relatively large scatter 
Table 1. Intertidal biomarkers used to estimate the amount of coseismic uplift and subsidence. SD: standard deviation.

\begin{tabular}{|c|c|c|c|c|c|}
\hline Bio-marker & $\begin{array}{l}\text { Number of } \\
\text { sites }\end{array}$ & $\begin{array}{c}\text { Number of } \\
\text { measurements }\end{array}$ & $\begin{array}{l}\text { SD of measurements at } \\
\text { individual sites, average } \\
\text { and range }(\mathrm{cm})\end{array}$ & $\begin{array}{l}\text { Height relative to } \\
\text { the upper } \\
\text { boundary of } \\
\text { Ostreidae }(\mathrm{cm})\end{array}$ & $\begin{array}{l}\text { Height relative to } \\
\text { pre-earthquake } \\
\text { mean sea level } \\
(\mathrm{cm})\end{array}$ \\
\hline Upper boundary of $P$. kraussii & 19 & 65 & $6.3(1.9-13.6)$ & 3 & 2 \\
\hline Upper boundary of Ostreidae & 21 & 212 & $4.0(0.9-8.0)$ & 0 & -1 \\
\hline Upper boundary of Mytilidae & 2 & 10 & $4.8(2.1-7.4)$ & -10 & -11 \\
\hline $\begin{array}{l}\text { Boundary between Chlorophyceae and } \\
\text { Phaeophyceae }\end{array}$ & 14 & 38 & $5.1(0.6-8.7)$ & -22 & -23 \\
\hline Total & 56 & 325 & & & \\
\hline
\end{tabular}

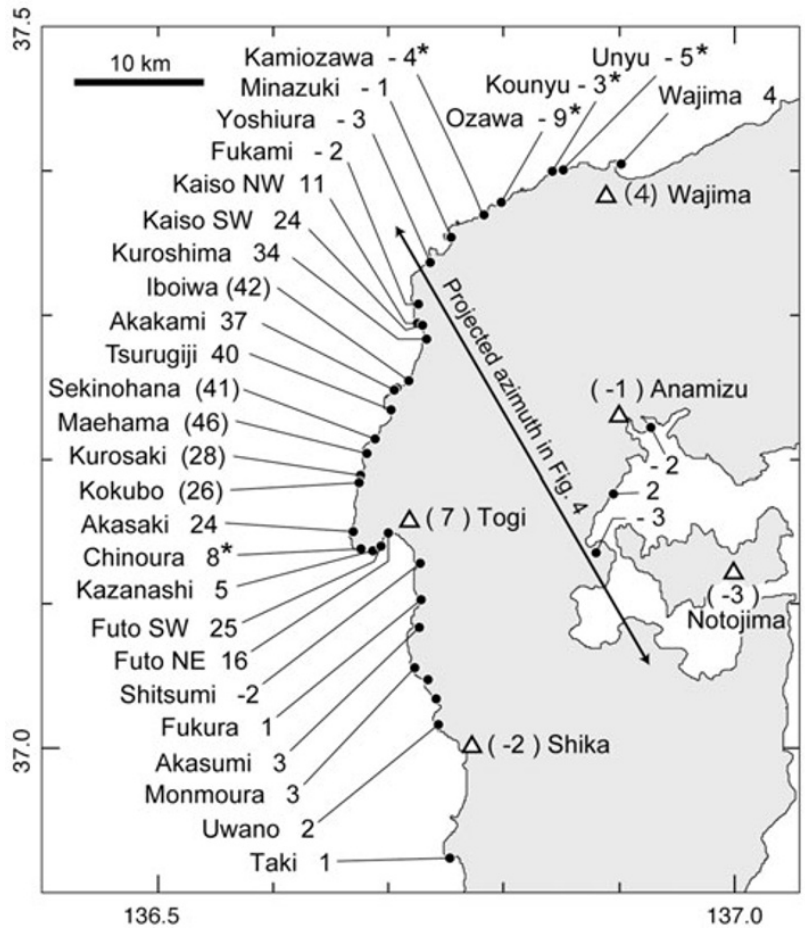

Fig. 3. Estimated coseismic vertical crustal displacements along the coast of the Noto Peninsula $(\mathrm{cm})$. Values are derived from measurements of Ostreidae colonies, the boundaries of algae (shown with an asterisk) along the northwest coast and at Chinoura, and P. kraussii colonies (shown in parentheses) along the rocky coast between Iboiwa and Kokubo. Triangles show permanent GPS stations operated by the Geographical Survey Institute with observed coseismic vertical movements in parentheses.

of measurements taken in the vicinity of the Futo area of the port of Togi may be due to long-period waves amplified within a small bay because we witnessed an unusually large change in the sea level: up to $25 \mathrm{~cm}$ with a period of approximately 10-20 $\mathrm{min}$ in and around the port located at the head of the bay. In the Anamizu area on the east coast of the peninsula, the amount of vertical crustal movements is almost zero or-at the most - a few centimeters of subsidence.

The overall deformation pattern along the coast of the Noto Peninsula suggests that the south-dipping source fault does not reach the surface; slip on the fault therefore terminates at depth. In accordance with the observed coastal deformation, no distinct earthquake-related onshore surface rupture was found.

\section{Fault Model Estimated from Coastal Move- ments}

To model the source fault of the Noto Hanto earthquake, we performed forward modeling to fit our observations in an elastic half space (Okada, 1992). We first fixed the strike at $58^{\circ}$, dip at $60^{\circ}$, and rake at $117^{\circ}$, following a fault plane solution determined by the USGS (2007). We also assumed a seismogenic depth of $12.5 \mathrm{~km}$ and a fault length of $14.5 \mathrm{~km}$. We then determined the location of the modeled fault based on both the location of the F-14 Fault and the 24-h aftershock distribution, excluding the apparent offfault moderate magnitude aftershocks and secondary aftershocks. The remaining unknown parameters, amount of net slip and depth to the fault tip, were assigned values by trial and error. Our modeling reveals that a net slip of $1.2 \mathrm{~m}$ and depth to the fault tip of $2 \mathrm{~km}$ give the best fit to our observations (Figs. 4 and 5), although our model yields a slightly smaller moment magnitude of $M_{\mathrm{w}}=6.5$ than seismological estimates.

\section{Discussion}

The amount of coseismic uplift associated with large earthquakes is normally estimated from the vertical extent of mortality of intertidal organisms, which becomes visible days or weeks after the earthquake (e.g., Nakamura et al., 1964; Carber et al., 1994; Meghraoui et al., 2004); however, in the present study we focused on the zonation of living colonies and succeeded in promptly determining the pattern and amount of minor vertical crustal movements of less than $40 \mathrm{~cm}$. These measurements were sufficiently accurate to constrain the source fault model under the fortunate condition that the coastline crosses the epicentral region. The success of this approach was probably reliant on the measurement of multiple intertidal organisms and the relatively small tidal variations in the study region.

From the viewpoint of disaster prevention and mitigation from triggered earthquakes after a large earthquake, the prompt determination of a well-constrained fault model is required to assess the probability of subsequent large off-fault aftershocks around the epicentral area (e.g., Toda, 2008). Detailed information on coseismic crustal deformation obtained immediately after large earthquakes is also indispensable in considering and monitoring possible postseismic movement. We are aware that instrumental surveys, such as leveling and modern GPS-based geodesy and SAR interferograms (InSAR), have a better accuracy and precision than our traditional method. Nonetheless, our method 


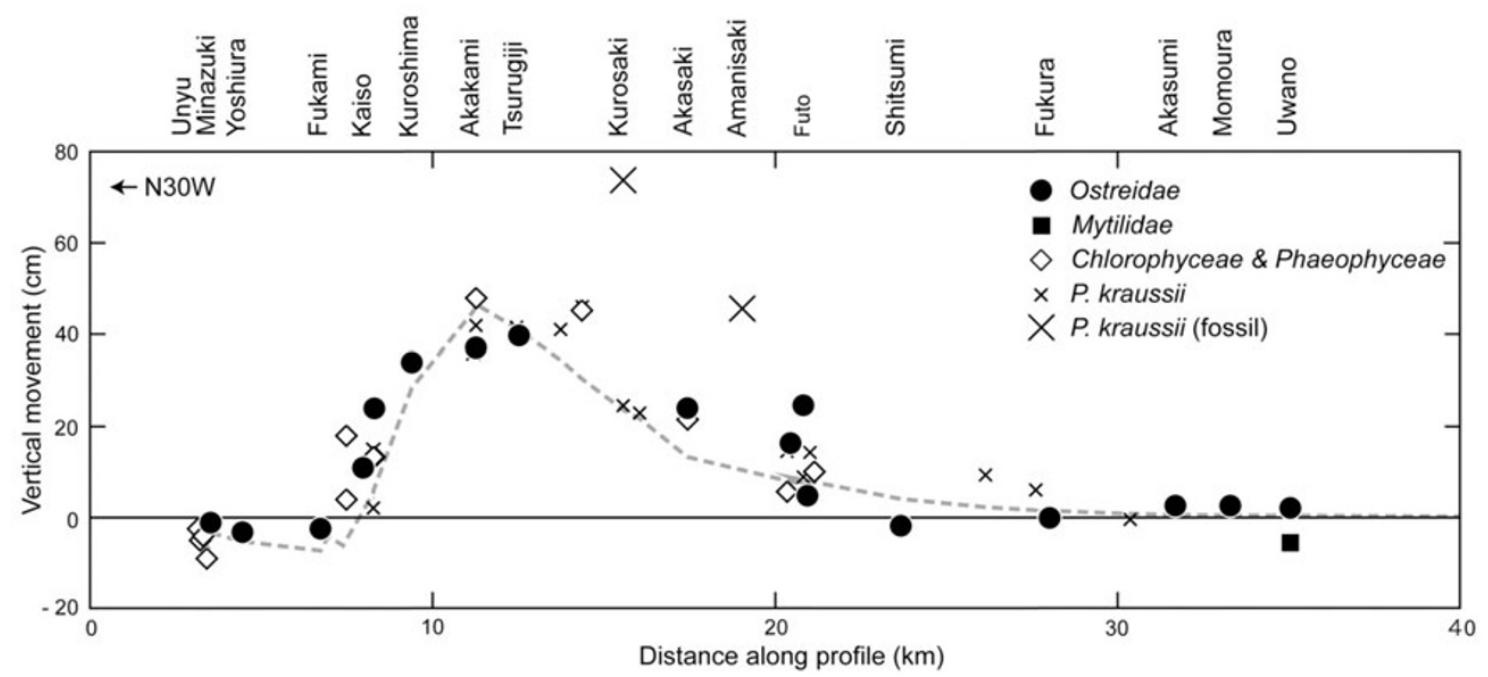

Fig. 4. Estimated coseismic vertical crustal displacements along the east coast of the peninsula, projected to the N30 ${ }^{\circ} \mathrm{W}$-trending line shown in Fig. 3 . Different symbols indicate different biomarkers used in the analysis. The dashed line denotes deformation along the coastline, as calculated using our best-fit fault model (see Fig. 5).

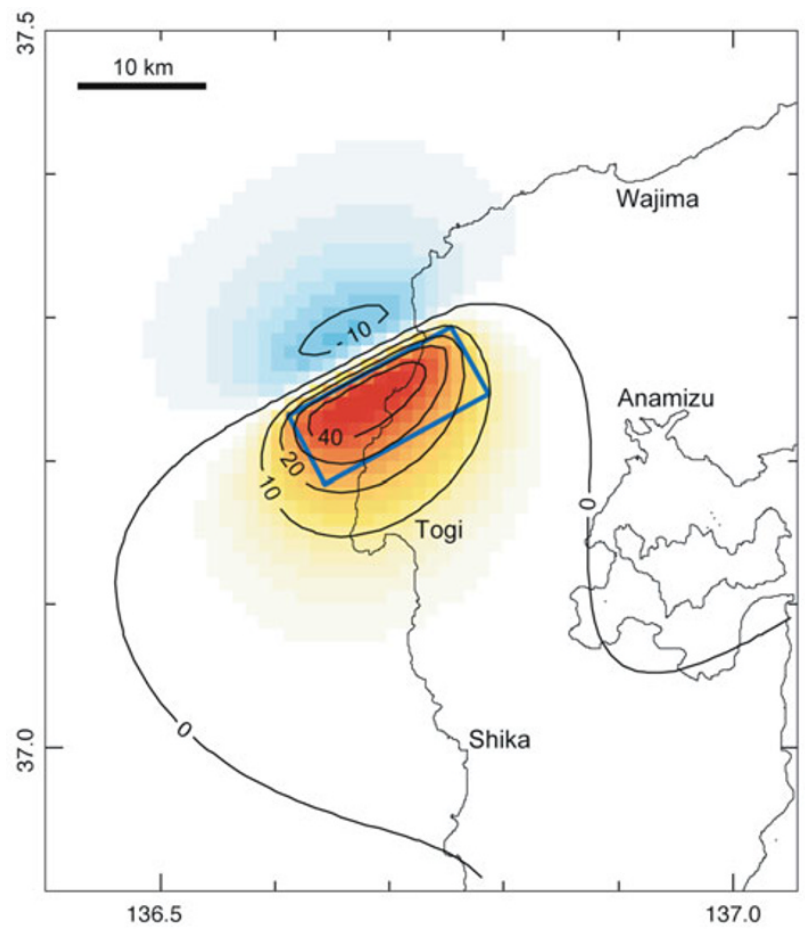

Fig. 5. Distribution of surface deformation estimated by our best-fit fault model. The blue rectangle shows the surface projection of the south-dipping source fault that is buried at a depth of $2 \mathrm{~km}$. Contour interval is $10 \mathrm{~cm}$.

has a number of advantages, including a much better spatial resolution than current GPS observations and a more rapid determination of surface deformations than leveling and InSAR. In addition, in terms of along-coast deformation, the spatial resolution of our method is still higher than any of the other geodetic methods; no other method can distinguish the details of crustal deformation associated with very shallow or surface faulting. We therefore emphasize that the most effective and reliable estimates of spatio-temporal crustal movement associated with large earthquakes is pro- vided by integrated analyses of data using traditional and instrumental methods.

Acknowledgments. We are thankful to H. Yamamoto, who kindly provided us with information on coastal movement along the southern Noto Peninsula. Discussions with Y. Namegaya and T. Maruyama helped us to adjust the sea level and estimate the crustal deformation. The clarity and completeness of the article were improved following reviews by two anonymous reviewers.

\section{References}

Carver, G. A., A. S. Jayko, D. W. Valentine, and W. H. Li, Coastal uplift associated with the 1992 Cape Mendocino earthquake, north California, Geology, 22, 195-198, 1994.

Geographical Survey Institute, http://www.gsi.go.jp/BOUSAI/isikawa/ taio/gps.html, 2007,

Katagawa, H., M. Hamada, S. Yoshida, H. Kadosawa, A. Mitsuhashi, Y. Kono, and Y. Kinugasa, Geological development of the east sea area of the Noto Peninsula district in the Neogene Tertiary to Quaternary, central Japan, J. Geogr., 114, 791-810, 2005 (in Japanese with English abstract).

Meghraoui, M., S. Maouche, B. Chemaa, Z. Cakir, A. Aoudia, A. Harbi, P. J. Alasset, A. Ayadi, Y. Bouhadad, and F. Benhamouda, Coastal uplift and thrust faulting associated with the $\mathrm{Mw}=6.8$ Zemmouri (Algeria) earthquake of 21 May, 2003, Geophys. Res. Lett., 31, L19605, doi:10.1029/2004GL02046, 2004.

Nakamura, K., K. Kasahara, and T. Matsuda, Tilting and uplift of an island, near the epicenter of the Niigata earthquake in 1964, J. Geodetic Soc. Jpn., 10, 172-179, 1964.

Okada, Y., Internal deformation due to shear and tensile faults in a halfspace, Bull. Seismol. Soc. Am., 82, 1018-1040, 1992.

Research Group for Active Fault of Japan, Active Fault in Japan: Sheet Maps and Inventories, rev. ed., 437 pp., Tokyo Univ. Press, Tokyo, 1991 (in Japanese with English abstract).

Shinkawa, H., Biology of Oyster, 167 pp., Kyobunsha, Tokyo, 1988 (in Japanese).

Toda, S., Coulomb stresses imparted by the 25 March $2007 M_{\mathrm{w}}=6.6$ Noto-Hanto, Japan, earthquake explain its 'butterfly' distribution of aftershocks and suggest a heightened seismic hazard, Earth Planets Space, 60, this issue, 1041-1046, 2008.

USGS, USGS fast moment tensor solution, magnitude 6.7-near the west coast of Honshu, Japan, 335, http://neic.usgs.gov/neis/ eq_depot/2007/eq_070325_aiae/neic_aiae_q.html, 2007.

Y. Awata (e-mail: awata-y@aist.go.jp), S. Toda, H. Kaneda, T. Azuma, H. Horikawa, M. Shishikura, and T. Echigo 